\title{
Determinants of Pulmonary Function Parameters: A Cross-Sectional Study Among Elite Athletes in Central Java, Indonesia
}

\author{
Mahalul Azam ${ }^{1}$, Sri Ratna Rahayu ${ }^{1}$, Rumini ${ }^{1}$, Yuni Wijayanti ${ }^{1}$, Arulita Ika Fibriana ${ }^{1}$, \\ Soedjatmiko $^{1}$, Heny Setyawati ${ }^{1}$, Muhamad Zakki Saefurrohim ${ }^{1}$, Moch. Thoriq Assegaf Al \\ Ayubi $^{2}$, Novaro Adeneur Tafriend ${ }^{3}$ \\ \{mahalul.azam@mail.unnes.ac.id ${ }^{1}$, sriratnarahayu@mail.unnes.ac.id ${ }^{2}$, rumini@mail.unnes.ac.id ${ }^{3}$ \} \\ Universitas Negeri Semarang, Semarang, Indonesia ${ }^{1}$ \\ UIN Syarif Hidayatullah ${ }^{2}$ \\ Gatot Soebroto Army Hospital ${ }^{3}$
}

\begin{abstract}
Our study aimed to define the determinants of athletes' Force Vital Capacity (FVC), Force Expiration Volume $\left(\mathrm{FEV}_{1}\right)$, and Peak Expiratory Flow (PEF). We conducted a cross-sectional study involved 134 athletes from 14 different sport disciplines. We observed age, sex, resting heart rate, body mass index, skinfold thickness, hypertension, and smoking status. The present study revealed that different sports disciplines influenced pulmonary function based on FVC, FEV1, FEV1/FVC, and $\mathrm{PEF}$. These findings add to evidence that there is a significant difference in pulmonary function among sports disciplines. Accuracy sports discipline observed had the highest score in the FEV1/FVC and PEF, while weightlifting showed the lowest FVC and FEV1. Ball game disciplines showed the highest score in FVC and FEV1/FVC. The present study concluded that the disciplines of sports were related to the pulmonary function test results. We observed that ball games had higher FVC and FEV1/FVC.
\end{abstract}

Keywords: pulmonary function; athletes; determinants; spirometry; sports.

\section{Introduction}

The pulmonary function test is the routine test for athletes that provides the ventilation volumes' parameters [1]. The test has become indispensable for preventing, diagnosing, and evaluating various respiratory impairments and analyzing the athlete's performance [1]. Previous studies reported that there is a higher level of pulmonary function parameters, such as vital capacity (VC), forced vital capacity (FVC), forced expiratory volume in one second (FEV1), and peak expiratory flow (PEF) in athletes compared to non-athletes [1-3]. The ventilation volume also varied among athletes based on sports; water sports and activities tend to have higher ventilation volume $[1,3,4]$. The study also concluded that pulmonary function performances are related to the athletes' physical performance [5].

Pulmonary function parameters in athletes also influenced by age [6, 7], body composition, history of lung and heart diseases, and physical activities[3, 8]. Regular physical activities will increase pulmonary function $[9,10]$. Anthropometric parameters are also related to pulmonary function[11]. 
There are well-established determinants of pulmonary function parameters; however, little is known in Indonesian elite athletes' setting. The present study aimed to explore the determinants of pulmonary function test parameters, i.e., FVC, FEV1, and PEF among elite athletes that participated in the training center in Central Java, Indonesia.

\section{Methods}

The present study conducted a cross-sectional study involved 134 athletes (mean age: 23.0 \pm 7.09 years old) attending the routine physical examination in the training center preparation facing the $20^{\text {th }}$ Indonesia national Olympic games. Study population involved fourteen kind of sports, i.e., archery $(n=9)$, motor racing $(n=4)$, shooting $(n=9)$, weightlifting $(n=7)$, beach volleyball $(n=3)$, roller sport $(n=10)$, gliding $(n=8)$, basketball $(n=6)$, taekwondo $(n=11)$, wushu $(n=15)$, boxing $(n=2)$, hockey $(n=20)$, baseball $(n=16)$, and softball $(n=14)$. Then, we categorized the sport disciplines as weightlifting; accuracy sports for shooting and archery; martial arts for taekwondo, wushu, and boxing; ball games sports for beach volleyball, basketball, hockey, baseball, and softball; racing sports for roller sports; and sports with instruments for motor racing and gliding.

All subjects that participated as athletes for more than two years were recruited in the study. While athletes with a history of lung and heart diseases and suffered from respiratory tract infection as well as pathological electrocardiographic appearance were excluded from the study.

\subsection{Procedures}

Present study was approved by the institutional review board Faculty of Medicine, Universitas Diponegoro, under the ID number 12/EC/KEPK/FK-UNDIP/I/2020. Study participants were informed regarding the study's measurement procedures and signed a consent to participate in the study. Demographical data such as age, sex, smoking status, and training history were acquired by questionnaire - no alcohol and caffeine consumption for 12 hours prior to the test. The measurements were conducted in the Sports Laboratory Center, Faculty of Sports Science, Universitas Negeri Semarang, with a temperature range between $18^{\circ} \mathrm{C}$ and $22{ }^{\circ} \mathrm{C}$ ), atmosphere pressure of $760 \mathrm{mmHg}$, relative humidity range 30-60\%. Pulmonary functions were measured by spirometer Pony FX (Cosmed, Roma, Italia). The parameters conform to the American Thoracic Society (ATS) / European Respiratory Society (ERS).

Spirometry test was done for athletes in the sitting position, used casual and comfort cloth, and used nose clips to avoid airflow leakage. Tests were done for three trials for every athlete and the highest value of FVC, FEV1, and PEF. The results of the pulmonary function parameters test were adjusted by anthropometric parameters, age, and sex. Weight and height of athletes were also measured to determine the body mass index (BMI). Percentage body fat was also measured using a bioimpedance body analyzer (BC-418 segmental body composition analyzer, Tanita, Illinois, USA). We also measured blood pressure as well as the resting heart rate. 


\subsection{Data analysis}

Numerical data with normal distribution presented as mean \pm SD, while non-Gaussian distributed data presented as median \pm interquartile range (IQR). Categorical data presented as frequency. A p-value $<0.05$ is considered statistically significant.

\section{Result and Discussion}

Table 1 showed us the subject's demographical characteristics of sex and smoking status. There was a significant difference in sex proportion in the ball games group. Male athletes were significantly dominant in the ball games group. Smoking status was also significantly different in the martial arts and sport disciplines which use instruments ( $P$ value $<0.05)$. All athletes in the martial arts were non-smoker, while a few non-martial arts athletes, i.e., $13.2 \%$, were smokers. The proportion of sport with instruments athletes as smokers was higher than non-smokers.

Table 1. Subject's characteristics

\begin{tabular}{|c|c|c|c|c|c|c|c|c|c|c|c|}
\hline \multirow{3}{*}{ Sports Category } & & \multicolumn{5}{|c|}{ Sex } & \multicolumn{5}{|c|}{ Smoking } \\
\hline & & \multicolumn{2}{|c|}{ Male } & \multicolumn{2}{|c|}{ Female } & \multirow{2}{*}{$\mathbf{O R}^{\dagger}$} & \multicolumn{2}{|c|}{ No } & \multicolumn{2}{|c|}{ Yes } & \multirow{2}{*}{$\mathbf{O R}^{\dagger}$} \\
\hline & & $\mathrm{n}$ & $\%$ & $\mathrm{n}$ & $\%$ & & $\mathrm{n}$ & $\%$ & $\mathrm{n}$ & $\%$ & \\
\hline \multirow{2}{*}{ Weightlifting } & No & 74 & 58.3 & 53 & 41.7 & \multirow{2}{*}{3.49} & 115 & 90.6 & 12 & 9.4 & \multirow{2}{*}{3.83} \\
\hline & Yes & 2 & 28.6 & 5 & 71.4 & & 5 & 71.4 & 2 & 28.6 & \\
\hline \multirow{2}{*}{ Accuracy } & No & 65 & 58.0 & 47 & 42.0 & \multirow{2}{*}{1.38} & 101 & 90.2 & 11 & 9.8 & \multirow[b]{2}{*}{1.45} \\
\hline & Yes & 11 & 50.0 & 11 & 50.0 & & 19 & 86.4 & 3 & 13.6 & \\
\hline \multirow{2}{*}{ Martial arts } & No & 62 & 58.5 & 44 & 41.5 & \multirow[b]{2}{*}{1.41} & 92 & 86.8 & 14 & 13.2 & \multirow{2}{*}{$0.87 *$} \\
\hline & Yes & 14 & 50.0 & 14 & 50.0 & & 28 & 100.0 & 0 & 0.0 & \\
\hline \multirow{2}{*}{ Ball games } & No & 40 & 47,6 & 44 & 52,4 & \multirow{2}{*}{$0.35^{*}$} & 111 & 88.8 & 14 & 11.2 & \multirow{2}{*}{0.88} \\
\hline & Yes & 36 & 72,0 & 14 & 28,0 & & 9 & 100.0 & 0 & 0.0 & \\
\hline \multirow{2}{*}{ Sports with instrument } & No & 71 & 56.3 & 55 & 43.7 & \multirow{2}{*}{0.78} & 117 & 92.9 & 9 & 7.1 & \multirow{2}{*}{$21.67 *$} \\
\hline & Yes & 5 & 62.5 & 3 & 37.5 & & 3 & 37.5 & 5 & 62.5 & \\
\hline \multirow{2}{*}{ Race sport } & No & 70 & 56.6 & 54 & 43.5 & \multirow{2}{*}{0.86} & 110 & 88.7 & 14 & 11.3 & \multirow{2}{*}{0.89} \\
\hline & Yes & 6 & 60.0 & 4 & 40.0 & & 10 & 100.0 & 0 & 0.0 & \\
\hline
\end{tabular}

${ }^{\dagger}$ Chi-square test. $* P<0.05$

Table 2 showed us the subject's characteristics of age, blood pressure, HR, fat percentage, and BMI. All subject's characteristics were different among the sports category except systolic blood pressure.

Table 2. Age, blood pressure, fat percentage, and body mass index based on sports category

\begin{tabular}{|c|c|c|c|c|c|c|}
\hline $\begin{array}{l}\text { Sports } \\
\text { Category }\end{array}$ & Age $^{*}$ & SBP & DBP & $\mathbf{H R}^{\ddagger}$ & $\begin{array}{c}\text { Fat } \\
\text { percentage }\end{array}$ & $\mathbf{B M I}^{*}$ \\
\hline Weightlifting & $24.00 \pm 5$ & $110.00 \pm 20$ & $80.00 \pm 10$ & $24.00 \pm 49^{* * *}$ & $78.00 \pm 38^{* * *}$ & $31.87 \pm 11.60^{* *}$ \\
\hline Accuracy & $20.00 \pm 10$ & $110.00 \pm 20$ & $70.00 \pm 10$ & $78.00 \pm 12$ & $63.50 \pm 38^{* *}$ & $24.02 \pm 5.13$ \\
\hline Martial arts & $20.00 \pm 6$ & $110.00 \pm 10$ & $70.00 \pm 15^{* *}$ & $78.00 \pm 8$ & $35.00 \pm 12^{* *}$ & $20.71 \pm 2.54^{* *}$ \\
\hline Ball games & $22.00 \pm 4^{* *}$ & $110.00 \pm 20$ & $70.00 \pm 10$ & $78.00 \pm 11$ & $38.50 \pm 20$ & $21.89 \pm 3.21$ \\
\hline
\end{tabular}




\begin{tabular}{|c|c|c|c|c|c|c|}
\hline $\begin{array}{l}\text { Sports with } \\
\text { instrument }\end{array}$ & $45.00 \pm 15^{* *}$ & $115.00 \pm 18$ & $80.00 \pm 10^{* *}$ & $79.00 \pm 16$ & $106.50 \pm 44^{* *}$ & $27.10 \pm 8.54^{*}$ \\
\hline Race sport & $17.50 \pm 2^{* *}$ & $110.00 \pm 13$ & $80.00 \pm 10$ & $79.00 \pm 12$ & $32.50 \pm 25^{*}$ & $21.23 \pm 3.17$ \\
\hline
\end{tabular}

Table 3 revealed that FEV1 was significantly influenced by age, while FVC was significantly influenced by sex.

Table 3. Pulmonary functional parameters based on age, sex, and BMI

\begin{tabular}{lllll}
\hline Variables & FVC & FEV1 & FEV1/FVC & PEF \\
\hline Age & $0.529 ; 0.055$ & $\mathbf{0 . 1 4 6 ; ~ 0 . 1 2 6 * *}$ & $0.490 ;-0.060$ & $0.884 ;-0.013$ \\
Male & $96.12 \pm 12.03$ & $104.00 \pm 19$ & $112.00 \pm 9$ & $101.00 \pm 27$ \\
Female & $\mathbf{8 7 . 0 2} \pm \mathbf{1 2 . 0 1} *$ & $92.00 \pm 17$ & $113.50 \pm 8$ & $99.50 \pm 24$ \\
BMI & $0.191 ; 0.114$ & $0.111 ; 0.138$ & $0.077 ;-0.153$ & $0.714 ;-0.032$ \\
\hline
\end{tabular}

BMI: body mass index;

The pulmonary function test results were significantly different in some sports categories (Table 4). The highest performance of FVC was found in the ball games group, i.e., $95.48 \pm 11.96 \%$, while the lowest was in the weightlifting group, i.e., $77.4 \pm 11.30 \%$. Accuracy sports discipline had the highest parameter in FEV1/FVC and PEF. In almost all kinds of pulmonary function parameters, weightlifting groups were significantly difference as the lowest in the FVC, FEV1, and PEF (Table 4).

Tabel 4. Pulmonary functional parameters based on the Sports category

\begin{tabular}{lllll}
\hline Sports Category & \multicolumn{1}{c}{ FVC } & \multicolumn{1}{c}{ FEV1 } & \multicolumn{1}{c}{ FEV1/FVC } & \multicolumn{1}{c}{ PEF } \\
\hline Weightlifting & $\mathbf{7 7 . 4 3} \pm \mathbf{1 1 . 3 0} * *$ & $\mathbf{8 8 . 0 0} \pm \mathbf{1 2} * *$ & $116.00 \pm 7$ & $\mathbf{9 3 . 0 0 \pm 3 2} *$ \\
Accuracy & $89.50 \pm 10.83$ & $98.00 \pm 20$ & $\mathbf{1 1 5 . 5 0 \pm 7 * *}$ & $\mathbf{1 1 2 . 0 0 \pm 2 4 * *}$ \\
Martial arts & $88.61 \pm 11.38$ & $96.50 \pm 17$ & $114.00 \pm 9$ & $98.00 \pm 29$ \\
Ball games & $\mathbf{9 5 . 4 8} \pm \mathbf{1 1 . 9 6} *$ & $101.50 \pm 19$ & $\mathbf{1 0 9 . 5 0 \pm 1 1 * *}$ & $98.00 \pm 27$ \\
Sports with instrument & $92.75 \pm 13.28$ & $98.50 \pm 23$ & $113.00 \pm 9$ & $106.50 \pm 28$ \\
Race sport & $97.70 \pm 13.26$ & $100.50 \pm 15$ & $111.00 \pm 8$ & $103.50 \pm 26$ \\
\hline
\end{tabular}

$* P<0.05$

$* * P<0.001$

The present study revealed that different sports influenced pulmonary function based on FVC, FEV1, FEV1/FVC, and PEF. These findings add to evidence that there is a significant difference in pulmonary function among sports disciplines. Accuracy sports discipline observed had the highest score in the FEV1/FVC and PEF. Weightlifting showed the lowest score in FVC and FEV1. Ball game disciplines showed the highest score in FVC and FEV1/FVC. However, we realized that these findings still had confounders since the athletes' heterogeneity characteristics, such as higher BMI in weightlifting athletes and a higher proportion of male athletes and younger age in the ball games, might influence the pulmonary function. Age, sex, and BMI were the most pivotal determinants of the pulmonary function parameters $[12,13]$. We must be concerned regarding these findings, in which FVC results are also influenced by female athletes and FEV1 influenced by the younger athletes, as shown in Table 3. 
The current study also observed that different disciplines of sport related to the pulmonary function are in line with the previous study $[14,15]$. A previous study also concluded that multicomponent exercises affect pulmonary function, even in diabetic subjects [16]. A dominant focus on respiratory muscle exercise like yoga increased pulmonary function [15].

A previous study revealed that physical fitness involved the pulmonary function related to high blood pressure; however, in the current study, we did not find this condition, perhaps of limited athletes being observed [17]. The duration of sports in which athletes conducted was also associated with the pulmonary function parameters [18].

\section{Conclusion}

The present study concluded that the disciplines of sports were related to the pulmonary function test results. We observed that ball games had higher FVC and FEV1/FVC. We also observed that age, sex, and BMI influenced the pulmonary function test, suggesting that future study must be done to elucidate factors related to the pulmonary function test parameters in different sports types comprehensively.

Conflicts of interest. The authors declared that there are no conflicts of interest.

Acknowledgments. The authors acknowledge the Indonesian Ministry of Research and Technology/ National Research and Inovation Agency for the research funding (Grant ID 13.23.3/UN37/PPK.3.1/2020. The authors also acknowledge the National Olympic Committee of Central Java, Indonesia for the permission to acquired data from athletes.

\section{References}

[1] Pezelj L, Milavic B, Erceg M (2019) Respiratory parameters in elite finn-class sailors. Montenegrin J Sport Sci Med 8:5-9

[2] Atan T, Akyol P, Cebi M (2012) Comparison of Respiratory Functions of Athletes Engaged in Different Sports Branches. turkish J Sport Exerc 14:76-81

[3] Mazic S, Lazovic B, Djelic M, Suzic-Lazic J, Djordjevic-Saranovic S, Durmic T, Soldatovic I, Zikic D, Gluvic Z, Zugic V (2015) Respiratory parameters in elite athletes - does sport have an influence? Rev Port Pneumol 21:192-197

[4] Durmic T, Lazovic B, Djelic M, Lazic JS, Zikic D, Zugic V, Dekleva M, Mazic S (2015) Sportspecific influences on respiratory patterns in elite athletes. J Bras Pneumol 41:516-522

[5] Lorenz DS, Reiman MP, Lehecka BJ, Naylor A (2013) What Performance Characteristics Determine Elite Versus Nonelite Athletes in the Same Sport? Sports Health 5:542-547

[6] Nikola F, Ognjen U, Nenad R, Marinković M (2013) Plućna funkcija rukometaša različitih dobnih kategorija. Hrvat športskomedicinski Vjesn 28:47-51

[7] Hraste M, Lozovina V, Lozovina M (2008) The Effect of Long-Term Training on Statistical and Dynamic Lungs Volumes and Capacities of Young Water-Polo Players. NAŠE MORE Znan časopis za more i Pomor 55:153-159

[8] Degens H, Rittweger J, Parviainen T, Timonen KL, Suominen H, Heinonen A, Korhonen MT (2013) Diffusion capacity of the lung in young and old endurance athletes. Int J Sports Med 34:1051-1057

[9] Riggs S (2012) More on Brain Oxygen and Lung Health: Vital Capacity. NACD J 25:1-2

[10] Singh A (2014) Comparison of Selected Respiratory Function Variables of Athletes Engaged in Individual Sports and Team Sports. Acad Sport Sch 3:1-4 
[11] Gold BD, Linde RR, Cudney PF (2012) KVM/370 in Retrospect. Proc - IEEE Symp Secur Priv 2012-July:13-23

[12] Agarwal D, Gupta PP (2007) A comparison of peak expiratory flow measured from forced vital capacity and peak flow meter manoeuvres in healthy volunteers. Ann Thorac Med 2:103-106

[13] Coates AL, Graham BL, McFadden RG, McParland C, Moosa D, Provencher S, Road J, Society CT (2013) Spirometry in primary care. Can Respir J 20:13-21

[14] Mahotra N, Shrestha L (2013) Effects Of Type Sports On Pulmonary Function Tests: A Comparative Study In Nepalese Settings. J Nobel Med Coll. https://doi.org/10.3126/jonmc.v2i1.7667

[15] Prakash S, Meshram S, Ramtekkar U (2007) Athletes, yogis and individuals with sedentary lifestyles; do their lung functions differ? Indian J Physiol Pharmacol 51:76-80

[16] Barrile SR, Valderramas CGM, Nunes AJ, Heubel AD, Arca EA, Iwamoto HCT, Martinelli B, Fernandes SA, Gimenes C (2017) Effects of multicomponent training on pulmonary function, functional capacity and quality of life in older adults with type 2 diabetes. Sport Sci Health 13:3946

[17] Dong Y, Jan C, Zou Z, et al (2020) Comprehensive physical fitness and high blood pressure in children and adolescents: A national cross-sectional survey in China. J Sci Med Sport 23:800-806

[18] Jeličić M, Uljević O, Zenić N (2017) Pulmonary function in prepubescent boys: The influence of passive smoking and sports training. Montenegrin J. Sport. Sci. Med. 